\section{The novel link between inflammatory enzyme C2GNT and the shedding of syndecan-1 in podocyte dysfunction}

\author{
Kirti Kaul, 1 Mohit Chopra,2 \\ Pamela De Angelis, ${ }^{3}$ Eva M. Kohner,2 \\ Rakesh Chibber² \\ 1German Diabetes Center, Leibniz Center \\ for Diabetes Research, Düsseldorf, \\ Germany; 2Institute of Biomedical and \\ Clinical Science, Peninsula College of \\ Medicine and Dentistry, St Luke's \\ Campus, University of Exeter, UK; \\ 3Department of Experimental Medicine \\ and Biochemical Sciences, University \\ of Perugia, Perugia, Italy
}

\section{Abstract}

Syndecan-1 is known to be a potential contributor to sub-clinical inflammation in diabetic nephropathy (DN). Loss of syndecan-1 from the surface of podocytes is thought to lead to cell dysfunction, which leads to the detachment of viable podocytes from the glomerulus, an early feature of DN. Although the mechanisms of constitutive syndecan-1 shedding have been addressed by several studies, the pathological mechanisms are less elucidated. The aim of this investigation is to consider the role of the 0-glycosylating enzyme C2GNT in syndecan1 shedding by podocytes. Conditionally immortalised human podocytes were used to study the effect of hyperglycaemia and C2GNT knockdown on syndecan-1 shedding by these cells. Hyperglycaemia induced C2GNT activity in podocytes results in increased 0 -glycosylation on the surface syndecan-1 in cells treated with high glucose compared to percentage of normal glucose $(219.5 \pm 145.7$ vs. $100 \%, \mathrm{P}<0.05)$. This increase in 0 -glycosylation is associated with an increase in the shedding of the syndecan-1 ectodomain by podocytes treated with high glucose compared to percentage of normal glucose $(118.2 \pm 7.1$ vs. $100 \%, \mathrm{P}<0.05)$. Moreover, podocytes manipulated for C2GNT knockdown show reduced syndecan-1 shedding when treated with high glucose compared to wild type cells treated with high glucose $(89.97 \pm 11.95$ vs. $118.2 \pm 7.17, \mathrm{P}<0.05)$. Our findings suggest that the activity of o-glycosylating enzyme C2GNT is raised in podocytes under diabetic conditions. We demonstrate for the first time a novel mechanism of pathological syndecan-1 shedding induced by C2GNT activity. This excess syndecan-1 shedding by podocytes can contribute to podocyte dysfunction.

\section{Introduction}

Diabetic nephropathy (DN) is a complication of the microvasculature of the kidneys. Clinical and epidemiological evidence suggests that up to $20 \%$ of patients with Type 1 diabetes (T1DM) and $40 \%$ of patients with Type 2 diabetes (T2DM) will develop DN. With the advent of the diabetes pandemic worldwide, the incidence of DN is also on a steep rise. ${ }^{1} \mathrm{DN}$ is closely associated with the development of cardiovascular disease in diabetes and contributes to early mortality as well as the need for renal replacement therapy and dialysis. ${ }^{2,3}$ This makes the understanding of the pathogenesis of this complication and need for novel therapeutic targets crucial.

Syndecans act as co-receptors with the potential to capture and locally concentrate Heparan Sulphate (HS)-binding ligands on the cell surface such as vascular endothelial growth factor (VEGF) and fibroblast growth factor (FGF). 4,5 Syndecan-1 is a single pass trans-membrane spanning protein known to mediate inflammation. Syndecan-1 has been localised mainly on epithelial cells, and to a lesser extent on other cells including endothelial cells and immune cells ${ }^{6,7}$ It has been observed that patients with DN have raised serum syndecan- 1 levels. ${ }^{8}$ This increase in the level of syndecan-1 ectodomain shedding into serum has been known to promote chemokine activity and the release of pro-inflammatory growth factors, which are normally associated with the 0-glycan chains on its ectodomain. 910

The syndecan- 1 molecule is made up of a cytoplasmic domain, a trans-membrane domain, comprising the juxtamembrane (JM) region, and an ectodomain. ${ }^{6}$ The cytoplasmic and transmembrane domains provide anchorage to the protein, while the ectodomain is heavily decorated with 0 -glycan structures terminating in heparan sulphate or chondroitin sulphate. Literature provides evidence of extensive 0-glycosylation seen in the ectodomain region, and the more moderate 0 -glycosylation on the transmembrane/JM domain of syndecan-1.

Sydecan-1 is also known to play an important role in influencing cell polarity, cell matrix interaction, anchorage of the cell to its basement membrane and bearing growth factors to appropriate receptors. ${ }^{11}$ Loss of syndecan-1 on epithelial cells is known to lead to loss of anchorage dependence and cell dysfunction. This phenomenon has been further studies as epithelium to mesenchyme transition (EMT) and cell migration. ${ }^{12}$ EMT is a complex process comprising multiple stages characterised by the loss of conventional cell surface markers. ${ }^{13}$ EMT is also recognised as a survival response whereby cells change morphology as a result of injury, but fail to undergo apoptosis.11,14

Podocytes or glomerular epithelial cells are
Correspondence: Rakesh Chibber, Institute of Biomedical and Clinical Science, Peninsula College of Medicine and Dentistry, University of Exeter, St Luke's Campus, Magdalen Road Exeter, EX1 2LU, UK.

Tel. +44.01392.262934 - Fax: +44.01392.62926.

E-mail: rakesh.chibber@pms.ac.uk

Keywords: core $2 \beta-1,6$-N-acetylglucosaminyltransferase, syndecan-1, oxidative stress, o-glycosylation, diabetes, diabetic nephropathy, inflammation.

Acknowledgements: the authors would like to thank Dr. Bing Mei-Yang for kindly providing the conditionally immortalised human podocyte cell line towards this work. This study was supported by the Peninsula College of Medicine and Dentistry, Universities of Exeter and Plymouth.

Contributions: KK, design and conception, data collection, analysis and interpretation of data, drafting the article and revising it critically for important intellectual content; MC, PA, data collection, revising the article critically for important intellectual content and final approval of the article to be published; EMK, revising the article critically for important intellectual content and final approval of the article to be published; RC design and conception, data interpretation, revision of article for important intellectual content and final approval of the article to be published.

Conflict of interests: the authors report no conflict of interests.

Received for publication: 10 September 2012 Accepted for publication: 10 September 2012.

This work is licensed under a Creative Commons Attribution NonCommercial 3.0 License (CC BYNC 3.0)

(C) Copyright K. Kaul et al., 2012 Licensee PAGEPress, Italy

Endocrinology Studies 2012; 2:e9

doi:10.4081/es.2012.e9

highly specialised quiescent cells that play a key role in forming the glomerular filtration barrier. ${ }^{15}$ Podocyturia or the presence of viable podocytes in the urine of patients, is an early pathological feature of DN. ${ }^{16}$ This pathological feature is considered a strong predictor of the progression of DN and associates closely with proteinuria and glomerulosclerosis.17-20 EMT has been implicated in podocyte dysfunction by several studies. ${ }^{21-23}$

Core-2- $\beta-1,6-\mathrm{N}$-acetylglucosaminyltransferase (C2GNT) is an inflammatory enzyme that brings about the addition of specific o-glycan structures to serine/threonine rich proteins thus forming core-2 structures. These 0-glycan structures have been recognised for both physiological and pathological contributions in 
cell-cell communication and the development of metastasis. ${ }^{24}$ Recently, there has been great interest in the role of C2GNT in the inflammatory response. C2GNT brings about changes in adhesion molecules such as P-selectin glycoprotein ligand 1 (PSGL-1) which in turn increases the extent of leukocyte homing and adhesion. ${ }^{25,26}$ The systemic link between diabetic retinopathy and nephropathy, and C2GNT activity has previously been established indicating strong correlations between the activity of the enzyme in leukocytes of the patients and the progression of the pathology.27-29 At the cellular level, C2GNT is known to bring about post-translational modifications that influence cell signaling, cell-cell communication and cell-matrix interaction via surface proteins. ${ }^{30}$ We propose that under hyperglycaemic conditions, C2GNT activity in podocytes is raised. Raised C2GNT activity leads to an increase in the 0 -glycosylation on the ectodomain as well as the JM stalk of the transmembrane domain of syndecan-1. This change in o-glycosylation influences shedding of the syndecan-1 ectodomain. The subsequent loss of syndecan1 by podocytes leads to podocyte dysfunction and detachment. This hypothesis provides a novel mechanism of podocyturia, and a novel potential therapeutic target for DN.

\section{Materials and Methods}

\section{Podocyte cell culture and treatment}

Conditionally immortalised human podocytes developed and described by Saleem et al. were cultured in RPMI containing $5.6 \mathrm{mM}$ glucose, supplemented with $10 \%$ fetal serum (FBS), insulin $(1 \mathrm{mg} / \mathrm{mL})$, transferrin $(0.55 \mathrm{mg} / \mathrm{mL})$ and selenium $(0.5 \mu \mathrm{g} / \mathrm{mL})$ supplement (Gibco, Paisley, UK) and 1\% penicillin and streptomycin. ${ }^{31}$ Podocytes were exposed to normal glucose (NG, $5.6 \mathrm{mM}$ glucose), or high glucose (HG, $35 \mathrm{mM}$ glucose) or to mannitol which served as an osmotic control (M, 35mM mannitol) for 24 hours. All cells were treated after 14 days of incubation at non-permissive temperature to ensure differentiation.

\section{Caspase-3 activity assay}

A caspase-3 activity assay kit (Sigma Aldrich, Dorset, UK) was used to measure caspase-3 activity in treated cells as an indication of cell death and apoptosis. This fluorometric kit measures endogenous caspase- 3 activity of a sample depending on its capacity to hydrolyse the substrate acetyl Asp-Glu-Val-Asp 7-amido4-methylcoumarin, Ac-DEVD-AMC. The resulting fluorescence is measured at an excitation wavelength of $360 \mathrm{~nm}$ and emission wavelengths of $460 \mathrm{~nm}$. Caspase-3 activity is calculated on the basis of a calibrated curve gener- ated by using AMC standards. Final activity is normalised against protein concentration. Each experiment was repeated on five separate occasions and the mean taken.

\section{Ethidium homodimer staining}

Another method to test cell viability based on the integrity of the cell membrane is by staining with ethidium homodimer (Molecular Probes, Paisley, UK). This stain cannot enter viable cells, however in dead cells it readily permeates and binds to nucleic acid. The fluorescence is highly pronounced once the stain binds DNA and can be measured at an excitation wavelength of $528 \mathrm{~nm}$ and emission wavelength of $617 \mathrm{~nm}$. The experiment was repeated on three separate occasions (in triplicates on each occasion) and the mean taken.

\section{Intracellular glucose \\ concentration-Amplex red assay}

Intracellular glucose concentration was measured using a commercially available kit, Amplex $\operatorname{Red}^{\circledR}$ Glucose assay kit (Invitrogen, Paisley, UK). The protocol and principle were provided by the manufacturers. To $50 \mathrm{~mL}$ of diluted cell lysates $50 \mu \mathrm{L}$ of reaction mixture containing 10 mM Amplex Red ${ }^{\circledR}, 10 \mathrm{U} / \mathrm{mL}$ horse radish peroxidise (HRP), $100 \mathrm{U} / \mathrm{mL}$ of glucose oxidase and $50 \mathrm{mM}$ of sodium phosphate buffer were added. This mixture was incubated at room temperature for 45 minutes under dark conditions. At the end of the incubation period the fluorescence was measured with a fluorometer (Spectra Max M2, Molecular Devices, Berkshire, UK) at an excitation wavelength of $530-560 \mathrm{~nm}$ and emission of $590 \mathrm{~nm}$. The concentration of intracellular glucose was calculated based on a standard curve generated as per supplier instructions. The calculated concentration of each sample was normalised using the protein concentration of the samples and the final results expressed as $\mu \mathrm{M}$ of glucose/ $\mu \mathrm{g}$ of protein. The experiment was repeated on ten separate occasions and the mean taken.

\section{General cellular reactive oxygen species measurement}

Cellular reactive oxygen species (ROS) was measured using a fluorogenic probe 2',7' dichlorofluorescein diacetate ( $\left.\mathrm{H}_{2} \mathrm{DCFDA}\right)$ (Molecular Probes, Paisley, UK). DCFDA readily enters cells and measures hydroxyl, peroxyl and other ROS. The probe is first deacetylated by esterases in the cytosol and this product is oxidized by ROS to a highly fluorescent entity, 2', 7' - dichlorofluorescein. This fluorescence in measured using a fluorometer (Spectra Max M2, UK) with excitation at $495 \mathrm{~nm}$ and emission at $529 \mathrm{~nm}$. The experiment was repeated on four separate occasions (in triplicates on each occasion) and the mean taken.

\section{Mitochondrial reactive oxygen} species measurement

Mitochondrial ROS was measured using a nonfluorescent probe Dihydrorhodamine 123 (DHR 123) (Molecular Probes, Paisley, UK). DHR 123 is uncharged and therefore can diffuse across membranes where it is oxidized to negatively charged rhodamine 123 . This oxidation product localises in the mitochondria and displays a fluorescence that can be detected using a fluorometer (Spectra Max M2, Molecular Devices, Berkshire, UK) with excitation at $500 \mathrm{~nm}$ and emission at $536 \mathrm{~nm}$. The experiment was repeated on four separate occasions (in triplicates on each occasion) and the mean taken.

Measurement of core-2- $\beta-1,6-\mathrm{N}-$ acetylglucosaminyltransferase activity

The assay was performed as previously described.32 Final concentrations of $40 \mathrm{mM} \mathrm{2-}$ ( $N$-morpholino) ethanesulfonic acid (MES), $\mathrm{pH} 7.0,0.5 \mu \mathrm{Ci}$ of UDP-[ $\left.{ }^{3} \mathrm{H}\right] \mathrm{GlcNAc}$ (Perkin Elmer, Cambrigeshire, UK) in $0.8 \mathrm{mM}$ UDPGlcNAc (Sigma Aldrich, Poole, UK), $80 \mathrm{mM}$ GlcNAc (Sigma Aldrich, Poole, UK) and $15 \mu \mathrm{L}$ of lysates were mixed with acceptor $0.8 \mathrm{mM} p$ nitrophenyl-Gal1-3GalNAc (Toronto Research Chemicals, Canada), for a positive reaction or without acceptor for negative reaction to give the endogenous activity of the enzyme. This reaction mixture was incubated at $37^{\circ} \mathrm{C}$ for 1 hour. At the end of the incubation period the reaction mixture was purified using column chromatography with C18 Sep-Pak columns (Agilent Technologies, Berkshire, UK) on a vacuum manifold (Sigma Aldrich, Poole, UK). The purified product was eluted using absolute methanol into scintillation cocktail (Perkin Elmer, Cambrigeshire, UK). The final elution was used to measure scintillation using a beta liquid scintillation counter (LS 6500, Beckman Coulter, High Wycombe, UK). The enzyme activity was expressed as $\mathrm{pmol} / \mathrm{h} / \mathrm{mg}$ of cell protein. The experiment was repeated on six separate occasions, and the mean taken.

\section{Measurement of shed syndecan-1 in} conditioned media

An enzyme-linked immunosorbent assay (ELISA) was used for the quantification of plasma Syndecan-1 (CD 138 ELISA Diaclone, distributed in the UK by $2 \mathrm{~B}$ Scientifics, Oxfordshire, UK). The kit is based on a sandwich ELISA. Monoclonal anti-CD138 antibody pre-coated microtiter strip plates was supplied by the manufacturer. Plasma samples and biotinylated anti-CD138 were added to these coated wells and incubated together at room temperature for 1 hour. At the end of this incubation period the wells were washed thorough- 


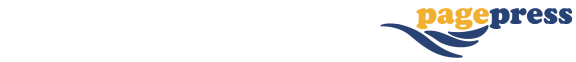

ly to remove excess and non-specific binding. This was followed by a 30 minute incubation with HRP conjugated streptavidin at room temperature. At the end of this incubation, the wells were washed thoroughly and $100 \mu \mathrm{L}$ of HRP substrate (TMB) added to all wells and allowed to develop for 12-15 minutes. This reaction was stopped by the addition of $100 \mu \mathrm{L}$ sulphuric acid, and the absorbance read at $450 \mathrm{~nm}$ wavelength. The concentration of shed syndecan-1 in given samples was calculated based on a standard curve generated using the standard provided by the manufacturers. The experiment was repeated on six separate occasions.

\section{Heparanase enzyme activity assay}

The activity of heparanase enzyme (HPSE) was measured in samples using an enzyme immunoassay (Heparan degrading Enzyme EIA Kit, Takara, Japan). The experiment was repeated on five separate occasions.

\section{Isolation of membrane and cytosolic fractions}

The membrane and cytosolic fractions were prepared based on the use of two separate lysis buffers and two different centrifugation speeds. The method developed and described by Evans et al. was used for this purpose. ${ }^{33}$

\section{Immunoprecipitation and western}

blot

An antibody raised against Syndecan-1 (Biolegend, Cambridge, UK) was coupled with Pan mouse IgG Dynabeads ${ }^{\circledR}$ (Invitrogen, Paisley, UK) and used to immunoprecipitate syndecan-1 from conditioned media overnight at $4^{\circ} \mathrm{C}$. A monoclonal antibody raised against o-glycan structures (Abcam, Cambridge, UK) was used to for the Western blot analysis. Antisyndecan-1 antibody was used as a loading control. The experiment was repeated on five separate occasions.
(A)

(B)
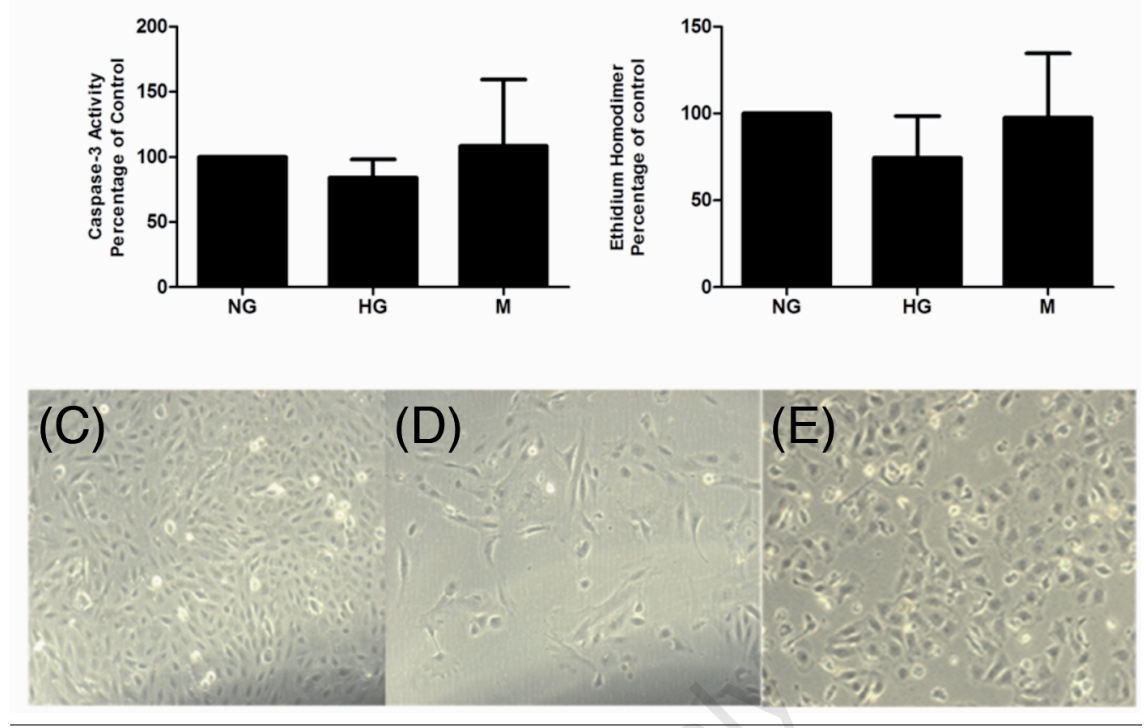

Figure 1. High glucose does not induce cell death in podocytes. Confluent differentiated podocytes were exposed to normal glucose (NG, $5.6 \mathrm{mM})$, high glucose (HG, $35 \mathrm{mM})$ and mannitol $(\mathrm{M})$ of the same concentration as an osmotic control $(\mathrm{M}, 35 \mathrm{mM})$ for a period of 24 hours. After the treatment, the cells were washed twice with PBS. The treated cells were either lysed for the measurement of caspase- 3 activity (A) or ethidium homodimer, (B) was added to cells grown in 96 well plates. Data are presented as mean \pm standard deviation of 5 separate experiments. ${ }^{*} \mathrm{P}<0.05 v s$. HG. C), D) and $\mathrm{E}$ ) represent undifferentiated podocytes, differentiated podocytes under normal glucose conditions and viable reattached cells after hyperglycaemic treatment for 24 hours.

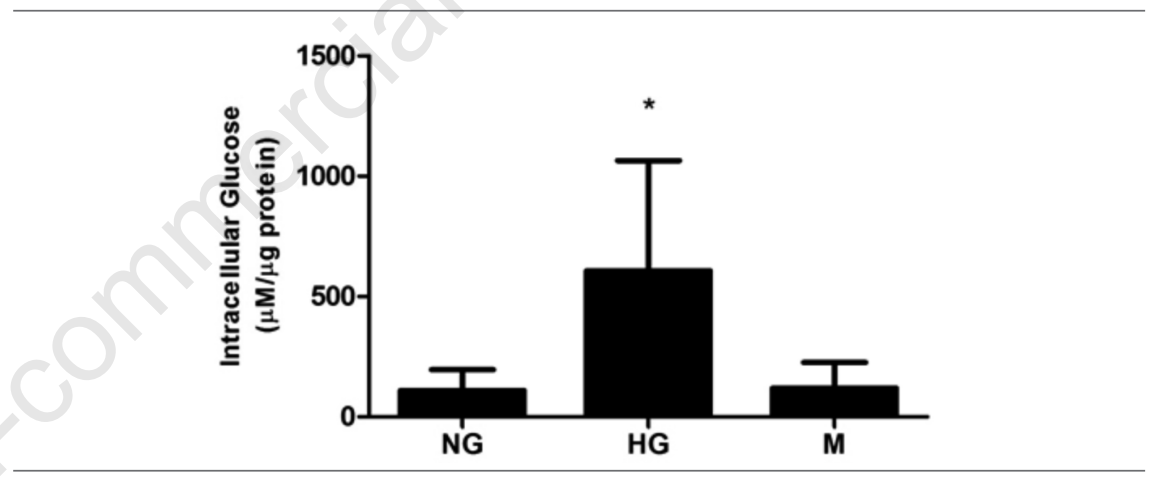

Figure 2. Exposure to high glucose increases intracellular concentration of glucose in podocytes. Confluent differentiated podocytes were exposed to NG, HG and M for a period of 24 hours. After the treatment, the cells were washed twice with PBS and lysed for the measurement of intracellular glucose using Amplex ${ }^{\circledR}$ Red glucose assay kit (Molecular Probe). Data are presented as mean \pm standard deviation of 10 separate experiments. ${ }^{*} \mathrm{P}<0.05$ vs. $\mathrm{NG}$.
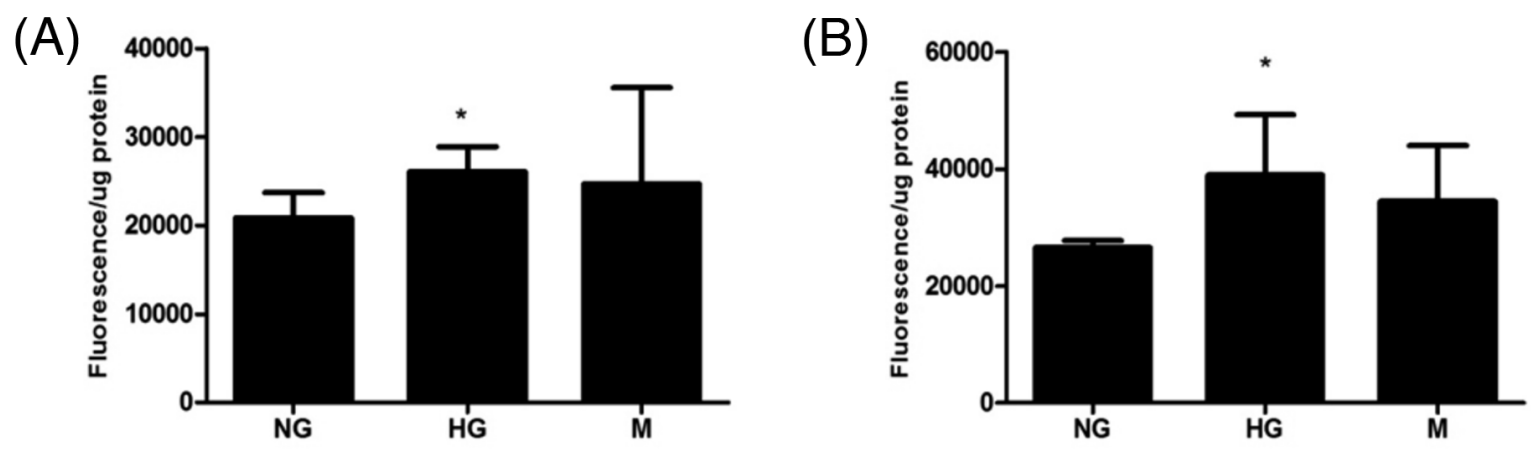

Figure 3. High glucose-induced cellular and mitochondrial ROS. Confluent differentiated podocytes were exposed to NG, HG and M for a period of 24 hours. After the treatment, the cells were washed twice with PBS and (A) probes DHR 123 and (B) DCFDA were incubated with the cells for 1 hour. Data are presented as mean \pm S.D. of 4 separate experiments. ${ }^{*} P<0.05 v s$. NG. 


\section{Transfection of podocytes}

Podocytes were grown and differentiated in 6well plates. To $1.5 \mathrm{~mL}$ sterile microfuge tube, $250 \mathrm{~mL}$ of serum free media was added followed by $6 \mathrm{~mL}$ of TransIT-siQuest ${ }^{\circledR}$ transfection reagent (Mirus, $\mathrm{UK}$ ), the contents were mixed briefly. To the microfuge tube $25 \mathrm{nM}$ of C2GNT siRNA was added and thoroughly mixed and then incubated at room temperature for $30 \mathrm{~min}$. The prepared transfection reagent with siRNA C2GNT (Santa Cruz, UK) was added drop by drop to approximately five different areas of the 6 -well plate. The dish was gently shaken to ensure thorough mixing and incubated for 48 hours for further treatment.

\section{Protein measurement}

Total protein was measured using the bicinchoninic acid (BCA) protein assay kit (Sigma, Poole, UK).

\section{Statistical analysis}

The statistical analysis was performed using GraphPad Prism. Statistical comparisons between groups were studied using student's ttest. A probability level of $\mathrm{P}<0.05$ was chosen as the threshold for acceptance of statistical significance. All data are represented as mean \pm standard deviation.

\section{Results}

\section{Cell death/toxicity}

Caspase-3 activity was neither raised nor significantly lowered in podocytes exposed to high glucose (HG) $(89.36 \% \pm 32.6)$ compared to percentage of normal glucose (NG) (100\%) and mannitol (M) (108.4 $\pm 50.3 \%)$, thus suggesting that a 24 hours HG exposure does not lead to apoptosis in podocytes in vitro (Figure 1A). This has previously been observed in a neuronal cell line. ${ }^{34}$ Similar results were observed when cell death on the basis of membrane integrity (ethidium homodimer) was considered (Figure 1B). HG and M (74.6 \pm 23.9 percentage of NG and $97.7 \pm 36.9$ percentage of NG) were not significantly different from NG 100\%). It was also observed that podocytes that were detached at the end of a 24 hours HG treatment reattached to culture dishes when replaced in NG (Figure 1E). These cells appear to be morphologically similar to undifferentiated podocytes (Figure 1C) and dissimilar to fully differentiated podocytes in NG (Figure 1D).

\section{Intracellular glucose}

Intracellular glucose concentration was measured and expressed as glucose $\mu \mathrm{M} / \mu \mathrm{g}$ protein. The intracellular concentration of glucose in podocytes exposed to $\mathrm{HG}$ was significantly higher $(606.3 \pm 485.1 \mu \mathrm{M} / \mu \mathrm{g}$ protein) com-

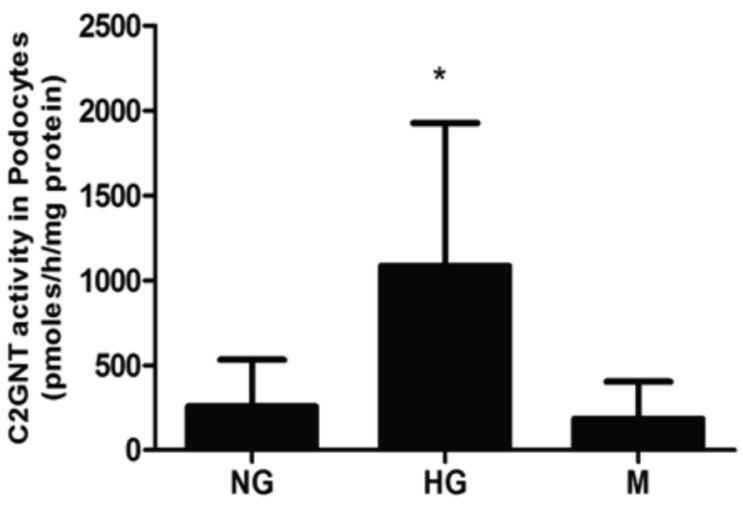

Figure 4. High glucose treatment raises C2GNT activity in podocytes. Confluent differentiated podocytes were exposed to NG, HG and M for a period of 24 hours. After the treatment, the cells were washed twice with PBS. The treated cells were lysed for the measurement of C2GNT activity. Data are presented as mean \pm S.D. of 6 separate experiments. ${ }^{*} \mathrm{P}<0.05$ vs. NG.

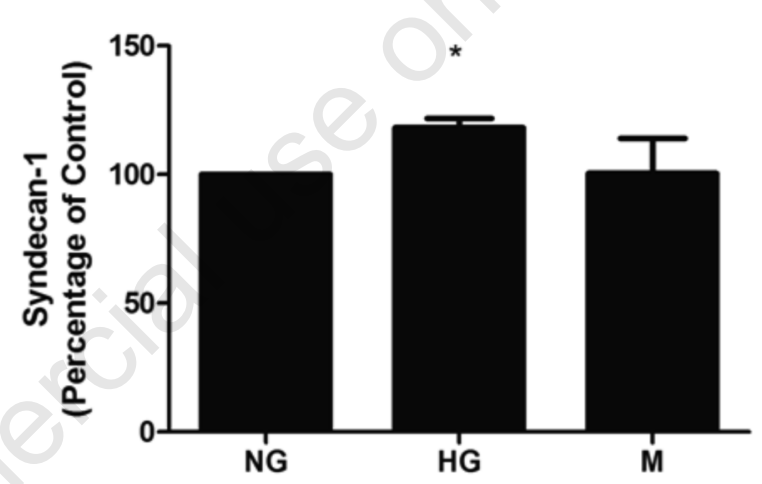

Figure 5. High glucose induced increase in Syndecan-1 shedding in the conditioned media of podocytes. Confluent differentiated podocytes were exposed to NG), HG and $\mathrm{M}$ for a period of 24 hours. After the treatment, conditioned media was collected and centrifuged at $2000 \mathrm{rpm}$ for 5 minutes to ensure the removal of cells and cellular debris. This conditioned media was then used for the measurement of shed syndecan-1. Data are presented as mean \pm S.D. of 10 separate experiments. ${ }^{*} \mathrm{P}<0.05$ vs. NG.

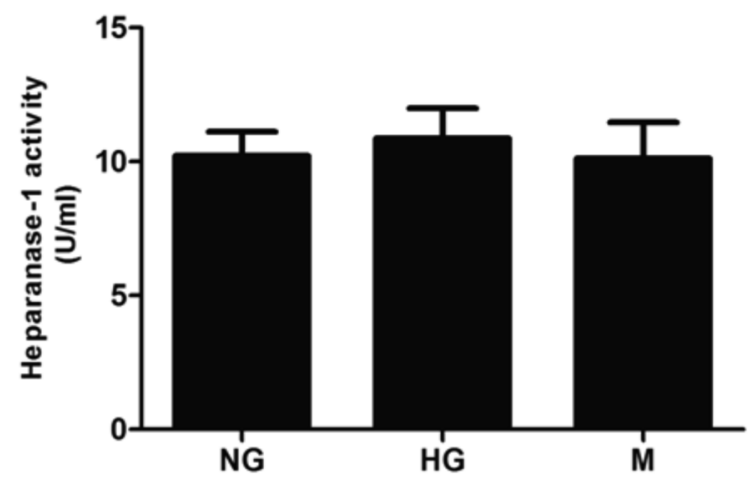

Figure 6. Heparanase (HPSE) activity in podocytes under hyperglycaemic conditions does not change. Confluent differentiated podocytes were exposed to NG, HG and $M$ for a period of 24 hours. After the treatment, the cells were washed twice with PBS. The treated cells were either lysed for the measurement of HPSE activity. Data are presented as mean \pm S.D. of 5 separate experiments. ${ }^{*} P<0.05 v s$. NG. 
pared to those exposed to NG $(110.1 \pm 85.3$ $\mu \mathrm{M} / \mu \mathrm{g}$ protein) and $\mathrm{M}(119.3 \pm 106.4 \mu \mathrm{M} / \mu \mathrm{g}$ protein) as depicted in Figure 2.

\section{Cellular and mitochondrial reactive oxygen species}

Both cellular as well as mitochondrial ROS appear to be raised in podocytes exposed to HG. Mitochondrial ROS levels was significantly raised in $\mathrm{HG}(38.981 \pm 8.274$ fluorescence/ $\mu \mathrm{g}$ protein) compared to those exposed to NG (25.690 1.132 fluorescence/ug protein) and $\mathrm{M}$ $(3.0070 \pm 9.498$ fluorescence/ug protein). Cellular ROS levels followed the same pattern with HG $v s$. NG $(20.853 \pm 2.853$ fluorescence/ $\mu \mathrm{g}$ protein vs. 26.116 \pm 2.780 fluorescence/ $\mu \mathrm{g}$ protein, $\mathrm{P}<0.05)$ and $\mathrm{M}(24.703 \pm 10,885$ fluorescence/ug protein) (Figure 3A, B).

\section{Core-2- $\beta-1,6-\mathrm{N}$-acetylglu- cosaminyltransferase activity in podocytes}

The activity of the enzyme C2GNT was found to be significantly raised in podocytes exposed to HG compared to those exposed to NG $(1.085 \pm 842.2 \mathrm{pmol} / \mathrm{hr} / \mathrm{mg}$ of protein $v s$. $257.4 \pm 274.9 \mathrm{pmol} / \mathrm{hr} / \mathrm{mg}$ of protein, $\mathrm{P}<0.05)$ and $\mathrm{M}(185 \pm 218.6 \mathrm{pmol} / \mathrm{hr} / \mathrm{mg}$ of protein) (Figure 4).

\section{High glucose-induced shedding of syndecan-1}

Syndecan-1 levels were significantly higher in podocytes treated with $\mathrm{HG}$ compared to $\mathrm{NG}$ $(118.2 \pm 7.1$ vs. $100, \quad \mathrm{P}<0.05)$ and $\mathrm{M}$ $(100.5 \pm 22.2, \mathrm{P}<0.05)$ as shown in Figure 5.

\section{Heparanase activity in treated podocytes}

HPSE activity did not change under hyperglycaemic conditions (Figure 6). HPSE activity in HG $(10.87 \pm 1.1 \mathrm{U} / \mathrm{mL})$ was not statistically different from NG $(10.22 \pm 0.9 \mathrm{U} / \mathrm{mL})$ and $\mathrm{M}$ $(10.12 \pm 1.3 \mathrm{U} / \mathrm{mL})$.

\section{Increased O-glycosylation on} cytoplasmic domain of syndecan-1

Figure 7 demonstrates a significant increase in 0-glycosylation on the JM region of the transmembrane domain of membrane bound syndecan-1. The level of glycosylation on syndecan-1 molecule on the basis of densiometric ratios was significantly higher in $\mathrm{HG}$ compared to $\mathrm{NG}(219.5 \pm 145.7$ vs. $100, \mathrm{P}<0.05)$ and $\mathrm{M}$ $(149.5 \pm 58.6)$.

\section{Effect of siRNA knockout of core-2- $\beta-1,6-\mathrm{N}$-acetylglu- cosaminyltransferase in podocytes on syndecan-1 shedding}

In order to assess the impact of C2GNT on syn- decan-1 shedding by podocytes, the differentiated cells transfected with siRNA specific for C2GNT were treated under NG, HG and M conditions. Figure 8 demonstrates that transfected cells treated with HG show less shed syndecan1 compared to $\mathrm{HG}$ in the wild type cell line (89.97 \pm 11.95 vs. $\quad 118.2 \pm 7.17, \quad \mathrm{P}<0.05)$. Transfected cells treated with NG did not result in a significantly different level of syndecan-1 shedding from wild type NG treatment $(100.0 \pm 2.52)$. This result provides evidence that C2GNT directly influences syndecan-1 shedding.

\section{Discussion}

DN poses a great threat to healthcare systems Worldwide as the leading cause of end-stage renal diseases (ESRD) and the most common cause for renal replacement therapy.1,35-37 Clinical evidence suggests that approximately $15-20 \%$ of patients with Type 1 diabetes and $30-40 \%$ of patients with Type 2 diabetes will develop ESRD. ${ }^{1,38} \mathrm{DN}$ is also closely associated with increased cardiovascular morbidity and mortality. ${ }^{39}$ Several factors and pathways con-

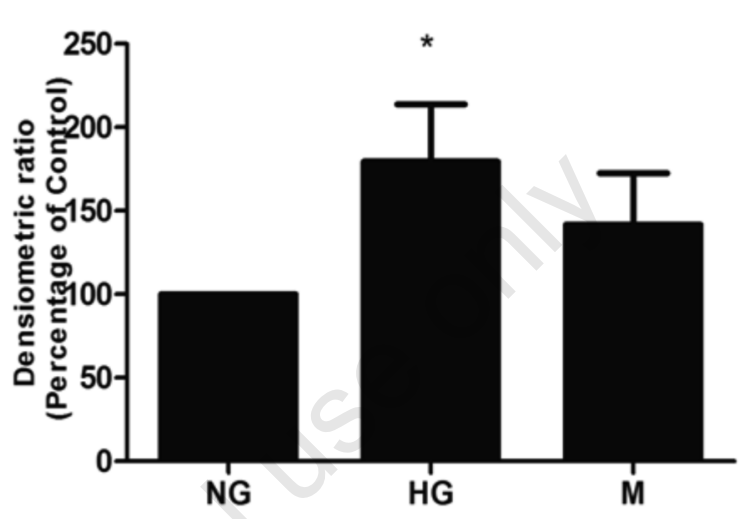

Figure 7. Ratio of O-glycosylation on syndecan-1 normalised against immunoprecipitated syndecan-1. Confluent differentiated podocytes were exposed to NG, HG and M for a period of 24 hours. After the treatment, the cells were washed twice with PBS. The treated cells were lysed specifically for membrane fraction extraction. Syndecan-1 was immunoprecipitated from this membrane fraction. This was followed by western blotting for O-glycan structures on the membrane bound syndecan-1 domain, and finally normalised to syndecan-1. Data are presented as mean \pm S.D. of three separate experiments. ${ }^{*} \mathrm{P}<0.05$ vs. NG.

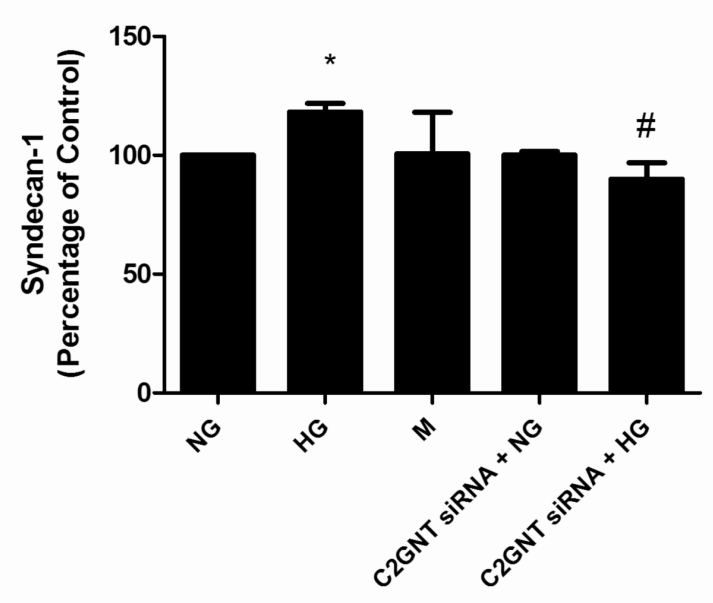

Figure 8. Syndecan-1 shedding under high glucose conditions by cells with knocked out C2GNT activity. Confluent differentiated podocytes were transfected with C2GNT siRNA. The transiently transfected cells were exposed to NG and HG for a period of 24 hours. The conditioned media was used for syndecan-1 quantification after 24 hours of treatment. Data are presented as mean $\pm S . D$. of three separate experiments. ${ }^{*} \mathrm{P}<0.05 v$ s. NG. 
tributing to the development and progression of DN have been established; however recent focus on the role of sub-clinical inflammation in the progression of this complication has lent interest to syndecan-1.40

The syndecan-1 molecule has been localised mainly on epithelial cells, and to a lesser extent on other cells including endothelial cells. ${ }^{6,7}$ The shedding of syndecan- 1 has been explored in literature for its pro-inflammatory properties. ${ }^{9}$ The ectodomain of the syndecan-1 molecule is known to be rich in heparan sulphate and chondroitin sulphate chains. These sugar chains interact with, harbour and concentrate inflammatory molecules such as VEGF and FGF.,5,9,41 The shedding of this ectodomain results in the release of pro-angiogenic and inflammatory factors within vasculature, this effect has been studied particularly in metastasis and more generally as a function of proteoglycans in diabetic complications. ${ }^{42,43}$

Proteoglycans, such as syndecan-1 play an important role in the regulation of permeability of the glomerular basement membrane and also influence cellular signalling and adhesion. ${ }^{44}$ Several groups have suggested that the shedding of syndecan-1 by podocytes leads to a change in morphology of these glomerular visceral epithelial cells. ${ }^{12,22}$ This transition, known as the epithelium to mesenchyme transition makes podocytes anchorage independent and is a potential contributor to podocyte dysfunction in the early development of DN.

Although several extracellular mechanisms such as proteolytic cleavage of syndecan-1 by matrix metalloproteinases that proteolytically cleave syndecan-1 ectodomain have been studied in metastasis as well as diabetes, posttranslational changes that contribute to increased syndecan-1 shedding remain unclear.45-48 HPSE is also known to influence the shedding of syndecan-1.49 In our study, exposure to high glucose increased the intracellular levels of glucose, and induced shedding of syndecan-1, but this was not associated with change in HPSE activity. This observation is consistent with the recent report by Masola et al. showing the potential of albumin and advanced glycation end-products, but not high glucose to induce HPSE expression in kidney tubular cells. ${ }^{50}$

An investigation by Schwager et al. has previously indicated that 0 -glycosylation on the juxtamembrane domain promotes shedding by proteases in angiotensin converting enzyme by an alternative mechanism. ${ }^{51}$ We propose that increased 0 -glycosylation on the juxtamembrane region of syndecan by C2GNT modulates syndecan-1 shedding under hyperglycaemic conditions.

In this study, we have shown that podocytes exposed to hyperglycaemic conditions show increased levels of intracellular glucose and raised production of ROS. Both these stimuli increase the activation of enzyme C2GNT, this is in accordance with our observation that C2GNT activity was raised in podocytes treated with HG. The increase in C2GNT activity leads to increased 0-glycosylation on various sites on the syndecan-1 molecule. We have associated the change in 0-glycosylation on membrane bound syndecan-1 with levels of shed syndecan-1 ectodomain. A study by Kliment et al has previously shown that oxidative stress leads to an increase in syndecan-1 shedding in lung tissue. ${ }^{52}$ Based on our previous work on the cross talk between TNF- $\alpha$, PKC- $\beta$, NADPH oxidase and C2GNT in leukocytes, it may be possible that in podocytes, hyperglycaemia and oxidative stress contribute to increased syndecan-1 ectodomain shedding via an increase in C2GNT activation. ${ }^{3}$

Sydecan-1 and C2GNT are both known to play an important role in cell-cell adhesion and cellmatrix adhesion. ${ }^{30}$ The loss of syndecan- 1 on podocytes triggers EMT and the cells become anchorage independent. We have also observed that these cells show a failure to undergo apoptosis. A 24 hours hyperglycaemic treatment results in the detachment of some podocytes, but when these detached cells are plated in media containing normal glucose concentration, the cells reattach to the culture dish and display an altered morphology. This is consistent with clinical studies that have observed the loss of viable podocytes in the urine of patients with DN. ${ }^{17}$ Furthermore, Figure 8 indicates for the first time, that C2GNT knockdown in podocytes and subsequent loss of C2GNT activity in these cells results in a decrease in syndecan-1 shedding by these cells under hyperglycaemic conditions. This work provides evidence for the first time of a direct link between C2GNT activity and syndecan- 1 shedding. Figure 9 summarises the role of C2GNT in the shedding of syndecan-1 ectodomain and subsequently the progression of DN.

The shed ectodomain of syndecan-1 may also

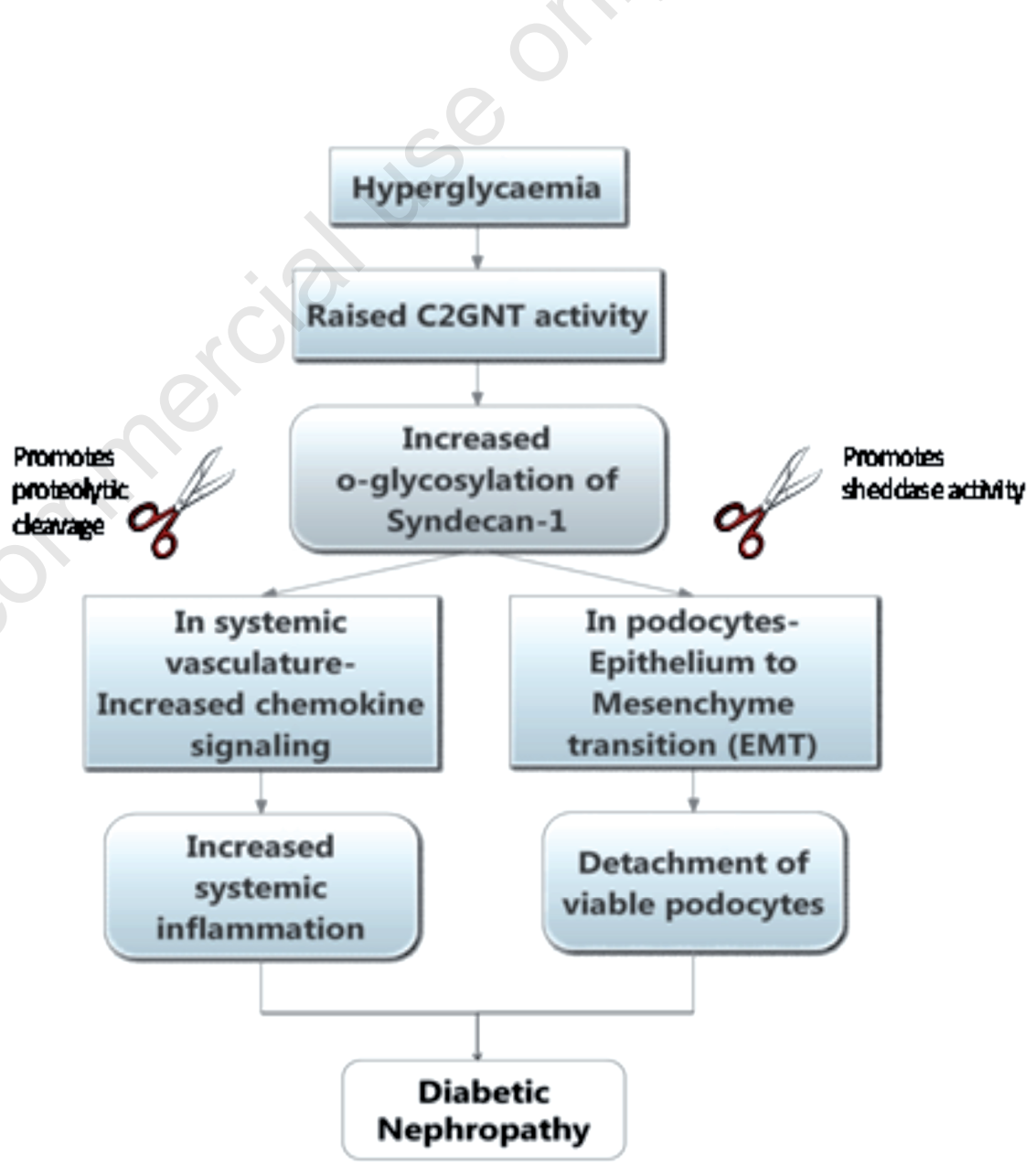

Figure 9. C2GNT and Syndecan-1: Link in DN. This flowchart depicts the hypothesis that we have investigated. We suggest that hyperglycaemia induced C2GNT activation results in increased $\mathrm{O}$-glycosylation on syndecan-1. This in turn influences the shedding of the syndecan-1 ectodomain. The shed ectodomain contributes to inflammation systemically as it enters the vasculature, this in turn contributes to the progression of DN. Locally in the kidneys, the loss of syndecan-1 from podocytes leads to EMT, which in turn results in detachment of podocytes from their basement membrane; a characteristic early feature of DN. 
contribute to DN as a result of its chemokine signalling locally in the glomerulus. We have previously shown in a clinical study that the activity of the inflammatory enzyme C2GNT is closely associated with the progression of DN. ${ }^{29}$ Therefore we conclude from this study that the enzyme C2GNT may contribute to DN both systemically via PMBCs and locally in podocytes via increased shedding of syndecan1. Future work would include the use of C2GNT inhibitor to test the change in loss of syndecan-1 by podocytes, this would allow us to recognise C2GNT as a potential therapeutic target for DN.

\section{References}

1. American Diabetes Associatio. Nephropathy in diabetes. Diabetes Care 2004;27:s79-s83.

2. Jensen T, Borch-Johnsen K, KofoedEnevoldsen A, Deckert T. Coronary heart disease in young Type 1 (insulin-dependent) diabetic patients with and without diabetic nephropathy: incidence and risk factors. Diabetologia 1987;30:144-8.

3. Moloney A, Tunbridge W, Ireland J, Watkins P. Mortality from diabetic nephropathy in the United Kingdom. Diabetologia 1983;25:26-30.

4. Rapraeger AC. Syndecan-regulated receptor signaling. J Cell Biol 2000;149:995-8.

5. Kato M, Wang H, Bernfield M, et al. Cell surface syndecan-1 on distinct cell types differs in fine structure and ligand binding of its heparan sulfate chains. J Biol Chem 1994;269:18881-90.

6. Bernfield M, Kokenyesi R, Kato M, et al. Biology of the syndecans: a family of transmembrane heparan sulfate proteoglycans. Annu Rev Cell Biol 1992;8:365-93.

7. Tkachenko E RJ, Simons M. Syndecans: new kids on the signaling block. Circ Res 2005;96:488-500.

8. Svennevig K, Kolset S, Bangstad HJ. Increased syndecan-1 in serum is related to early nephropathy in type 1 diabetes mellitus patients. Diabetologia 2006;49: 2214-6.

9. Goette M. Syndecans in inflammation. FASEB J 2003;17:575-91.

10. Alexopoulou AN, Multhaupt HAB, Couchman JR. Syndecans in wound healing, inflammation and vascular biology. Int J Biochem Cell Biol 2007;39:505-28.

11. Kalluri R, Weinberg RA. The basics of epithelial-mesenchymal transition. J Clin Invest 2009;119:1420-8.

12. Kato M, Saunders S, Nguyen H, Bernfield M. Loss of cell surface syndecan-1 causes epithelia to transform into anchorageindependent mesenchyme-like cells. Mol
Biol Cell 1995;6:559-76.

13. Thiery JP, Sleeman JP. Complex networks orchestrate epithelial-mesenchymal transitions. Nat Rev Mol Cell Biol 2006;7:13142.

14. Robson EJD, Khaled WT, Abell K, Watson CJ. Epithelial-to-mesenchymal transition confers resistance to apoptosis in three murine mammary epithelial cell lines. Differentiation 2006;74:254-64.

15. Pavenstädt H, Kriz W, Kretzler M. Cell biology of the glomerular podocyte. Physiol Rev 2003;83:253-307.

16. Pagtalunan ME, Miller PL, Jumping-Eagle $\mathrm{S}$, et al. Podocyte loss and progressive glomerular injury in type II diabetes. J Clin Invest 1997;99:342-8.

17. Nakamura T, Ushiyama C, Suzuki S, et al. Urinary excretion of podocytes in patients with diabetic nephropathy. Nephrol Dial Transplant 2000;15:1379-83.

18. Yu D, Petermann A, Kunter U, et al. Urinary podocyte loss is a more specific marker of ongoing glomerular damage than proteinuria. J Am Soc Nephrol 2005; 16:1733-41.

19. Kriz WL, Lemley KW. The role of the podocyte in glomerulosclerosis. Curr Opin Nephrol Hypertens 1999;8:489-97.

20. Petermann AT, Pippin J, Krofft R, et al. Viable podocytes detach in experimental diabetic nephropathy: potential mechanism underlying glomerulosclerosis. Nephron Exp Nephrol 2004;98:114-23.

21. Li Y, Kang YS, Dai C, et al. Epithelial-tomesenchymal transition is a potential pathway leading to podocyte dysfunction and proteinuria. Am J Pathol 2008;172: 299-308.

22. Yamaguchi Y, Iwano M, Suzuki D, et al. Epithelial-mesenchymal transition as a potential explanation for podocyte depletion in diabetic nephropathy. Am J Kidney Dis 2009;54:653-64.

23. Reidy K, Susztak K. Epithelial mesenchymal transition and podocyte loss in diabetic kidney disease. Am J Kidney Dis 2009; 54:590-3.

24. Ghazarian H, Idoni B, Oppenheimer SB. A glycobiology review: carbohydrates, lectins and implications in cancer therapeutics. Acta Histochemica 2011;113:236-47.

25. Snapp KR, Heitzig CE, Ellies LG, et al. Differential requirements for the 0 -linked branching enzyme core 2 b1-6-N-glucosaminyltransferase in biosynthesis of ligands for E-selectin and P-selectin. Blood 2001;97:3806-11.

26. Ellies LG, Tsuboi S, Petryniak B, et al. Core 2 oligosaccharide biosynthesis distinguishes between selectin ligands essential for leukocyte homing and inflammation. Immunity 1998;9:881-90.

27. Ben-Mahmud BM, Mann GE, Datti A, et al. Tumor necrosis factor-a in diabetic plasma increases the activity of core 2 GlcNAc-T and adherence of human leukocytes to retinal endothelial cells. Diabetes 2004; 53:2968-76.

28. Ben-Mahmud B, Chan W, Abdulahad R, et al. Clinical validation of a link between TNF-a and the glycosylation enzyme core 2 GlcNAc-T and the relationship of this link to diabetic retinopathy. Diabetologia 2006;49:2185-91.

29. Kaul K HA, Shore A, Tarr JM, et al. The inflammatory enzyme C2GNT contributes to the progression of diabetic nephropathy. NDT Plus 2011;4.

30. Stone EL, Ismail $\mathrm{MN}$, Lee $\mathrm{SH}$, et al. Glycosyltransferase function in core 2-type protein 0 glycosylation. Mol Cell Biol 2009;29:3770-82.

31. Saleem MA, O’Hare MJ, Reiser J, et al. A conditionally immortalized human podocyte cell line demonstrating nephrin and podocin expression. J Am Soc Nephrol 2002;13:630-8.

32. Chibber R, Ben-Mahmud BM, Coppini D, et al. Activity of the glycosylating enzyme, core 2 GlcNAc (betal,6) transferase, is higher in polymorphonuclear leukocytes from diabetic patients compared with agematched control subjects: relevance to capillary occlusion in diabetic retinopathy. Diabetes 2000;49:1724-30.

33. Wisher MH, Evans WH. Functional polarity of the rat hepatocyte surface membrane. Isolation and characterization of plasmamembrane subfractions from the bloodsinusoidal, bile-Canalicular and contiguous surfaces of the hepatocyte. Biochem J 1975;146:375-88.

34. Russell JW, Golovoy D, Vincent AM, et al. High glucose-induced oxidative stress and mitochondrial dysfunction in neurons. FASEB J 2002;16:1738-48.

35. Gross JL, de Azevedo MJ, Silveiro SP, et al. Diabetic nephropathy: diagnosis, prevention, and treatment. Diabetes Care 2005;28:164-76.

36. Mitch WE. Treating diabetic nephropathy are there only economic issues? New Eng J Med 2004;351:1934-6.

37. Gordois A, Scuffham P, Shearer A, Oglesby A. The health care costs of diabetic nephropathy in the United States and the United Kingdom. J Diabetes Complications 2004;18:18-26.

38. Selby JV, Fitz-Simmons SC, Newman JM, et al. The natural history and epidemiology of diabetic nephropathy. JAMA 1990;263: 1954-60.

39. de Zeeuw D, Remuzzi G, Parving H-H, et al. Albuminuria, a therapeutic target for cardiovascular protection in type 2 diabetic patients with nephropathy. Circulation 2004;110:921-7.

40. Kaul K, Hodgkinson AM, Tarr JM, et al. Is 
inflammation a common retinal-renalnerve pathogenic link in diabetes? Curr Diab Rev 2010;6:294-303.

41. Filla MS, Dam P, Rapraeger AC. The cell surface proteoglycan syndecan-1 mediates fibroblast growth factor-2 binding and activity. J Cell Physiol 1998;174:310-21.

42. Nieuwdorp M, Mooij HL, Kroon J, et al. Endothelial glycocalyx damage coincides with microalbuminuria in type 1 diabetes. Diabetes 2006;55:1127-32.

43. Nieuwdorp $M$, van Haeften TW, Gouverneur MCLG, et al. Loss of endothelial glycocalyx during acute hyperglycemia coincides with endothelial dysfunction and coagulation activation in vivo. Diabetes 2006;55:480-6.

44. Björnson Granqvist A, Ebefors K, Saleem MA, et al. Podocyte proteoglycan synthesis is involved in the development of nephrotic syndrome. Am J Physiol Renal Physiol 2006;291:F722-F30.

45. Dhodapkar MV, Kelly T, Theus A, et al.
Elevated levels of shed syndecan-1 correlate with tumour mass and decreased matrix metalloproteinase- 9 activity in the serum of patients with multiple myeloma. Br J Haematol 1997;99:368-71.

46. Endo K, Takino T, Miyamori $\mathrm{H}$, et al. Cleavage of syndecan- 1 by membrane type matrix metalloproteinase-1 stimulates cell migration. J Biol Chem 2003;278:4076470.

47. Fitzgerald ML, Wang Z, Park PW, et al. Shedding of syndecan-1 and -4 ectodomains is regulated by multiple signaling pathways and mediated by a timp3-sensitive metalloproteinase. J Cell Biol 2000;148:811-24.

48. Chan SCH, Shum DKY, Ip MSM. Sputum sol neutrophil elastase activity in bronchiectasis: differential modulation by syndecan-1. Am J Respir Crit Care Med 2003;168:192-8.

49. Yang Y, MacLeod V, Miao H-Q, et al. Heparanase enhances syndecan-1 shed- ding. J Biol Chem 2007;282:13326-33.

50. Masola V, Gambaro G, Tibaldi E, et al. Regulation of heparanase by albumin and advanced glycation end products in proximal tubular cells. Biochim Biophys Acta 2011;1813:1475-82.

51. Schwager SLU, Chubb AJ, Scholle RR, et al. Modulation of juxtamembrane cleavage ("Shedding") of angiotensin-converting enzyme by stalk glycosylation: evidence for an alternative shedding protease. Biochemistry1999;38:10388-97.

52. Kliment CR, Englert JM, Gochuico BR, et al. Oxidative stress alters syndecan-1 distribution in lungs with pulmonary fibrosis. J Biol Chem 2009;284:3537-45.

53. Tarr JM, Ding N, Kaul K, et al. Cellular crosstalk between TNF-a, NADPH oxidase, PKCb2, and C2GNT in human leukocytes. Cell Signal 2012;24:873-8. 